Himat Vaghadia MB BS MHSC FCA FRCPC, ${ }^{*} \dagger$

Linda Collins MB BCH BAO FFARCSI, *

Huiying Sun BSc, $\$$

G.W.E. Mitchell MB CHB MRCOG FRCS(Ed) FRCSC $\ddagger$

\section{Selective spinal anesthesia for outpatient laparoscopy. IV: Population pharma- codynamic modelling}

Purpose: To apply a population pharmacodynamic model to small-dose hypobaric spinal anesthesia for outpatient laparoscopy.

Methods: The level of spinal analgesia after spinal blockade with small-dose (20-25 mg) hypobaric lidocaine was assessed by means of pinprick in patients undergoing outpatient laparoscopy. In 57 patients, 385 measurements were available for analysis. We first modelled the data for each patient with a mixed-effects model described by Schnider (Model I). The population mean parameters, inter-individual variance, and residual variance were estimated. Clinically important endpoints (time to reach $T_{10}$ (onset), time to maximal level, duration and maximally attained level) of each patient were calculated based on the estimated time course of analgesia level for each patient. The model was used to predict the later data with respect to level of spinal analgesia of each patient from fits based on the observed data in the first $75 \mathrm{~min}$.

Results: The mean \pm SD onset time was $8.3 \pm 1.9$ min, time to maximal level was $20.8 \pm 5.3$ min, duration of effect was $37.9 \pm 13.1 \mathrm{~min}$, and mean maximal level was $T_{5}$. There was a good correlation $\left(R^{2}=0.90\right)$ between the observed levels of analgesia and those predicted from the model. Data from the first 75 min predicted the later observed data for each patient moderately well $\left(R^{2}=0.38\right)$.

Conclusion: A population pharmacodynamic model was applied to low-dose hypobaric lidocaine spinal anesthesia. Clinically important endpoints were determined and forecasting of later data with respect to level of spinal analgesia was attempted. Such an approach may be useful in the management of low-dose spinal anesthetic techniques in outpatients.

Objectif : Montrer l'application d'un modèle pharmacodynamique de population à la rachianesthésie hypobare à faible dose, administrée pour la laparoscopie ambulatoire.

Méthode : Le niveau de rachianalgésie, après bloc rachidien avec de petites doses (20-25 mg) de lidocaïne hypobare, a été évalué par un test de sensibilité à la douleur chez des patients qui devaient subir une laparoscopie ambulatoire. L'analyse a porté sur 385 mesures pour 57 patients. Nous avons d'abord modélisé les données pour chaque patient selon un modèle à effets mixtes décrit par Schnider (Modèle I). Les paramètres de la moyenne, la variance interindividuelle et la variance résiduelle de la population ont été estimés. Les mesures d'importance clinique (le temps nécessaire pour atteindre $T_{10}$ (le début d'action), le temps nécessaire pour atteindre le niveau maximal, le niveau maximal obtenu et sa durée) ont été calculées sur la base de la durée estimée de l'analgésie pour chacun. Le modèle a servi à prédire des données subséquentes sur le niveau de rachianalgésie à partir d'ajustements fondés sur les données observées pendant les 75 premières min.

Résultats : Le délai moyen d'installation \pm l'écart type a été de $8,3 \pm 1,9 \mathrm{~min}$, le temps pour atteindre le niveau maximal a été de 20,8 \pm 5,3 min, la durée de l'effet a été de 37,9 \pm 13 , I min et le niveau maximal moyen a été $T_{5}$. Une bonne corrélation existait $\left(R^{2}=0,90\right)$ entre les niveaux d'analgésie observés et les niveaux prédits par le modèle. Les données des 75 premières min ont permis de faire une prédiction modérément bonne des observations individuelles ultérieures $\left(R^{2}=0,38\right)$.

Conclusion : Un modèle pharmacodynamique de population a été appliqué à la rachianesthésie à faibles doses avec lidocaïne hypobare. Les paramètres d'importance clinique ont été déterminés et la prédiction de données ultérieures concernant le niveau de rachianalgésie a été testée. Une démarche semblable peut être utile aux techniques de rachianesthésie à faibles doses chez des patients externes.

From the Departments of Anesthesia, ${ }^{*}$ Health Care and Epidemiology, $†$ Gynecology $\ddagger$ and Statistics, $\$$ Vancouver General Hospital, University of British Columbia, Vancouver, British Columbia, Canada.

Address correspondence to: Dr. Himat Vaghadia, Department of Anesthesia (Room 3200), Vancouver General Hospital, 3rd Floor - 910

West 10th Ave, Vancouver, British Columbia, V5Z 4E3 Canada. Phone: 604-875-4304; Fax: 604-875-5209; E-mail: hvaghadi@vanhosp.bc.ca Accepted for publication October 29, 2000. 
I NCREASINGLY, it is recognized that conventional dose spinal anesthesia may be unsuitable for short to medium duration outpatient procedures because of prolonged motor block and the consequent risk of unplanned admission. ${ }^{1}$ In our institution, we have achieved success with low-dose techniques that facilitate rapid recovery and discharge after spinal anesthesia for laparoscopy. ${ }^{2-3}$ However, with the use of low-dose spinal anesthesia, there may be concern that individual variability in response may result in some patients not obtaining adequate anesthesia. One method to resolve this dilemma is to utilize population based pharmacodynamic modelling to characterise individual responses and the variability in response within a defined population. ${ }^{4}$ Based on such modelling, important clinical endpoints or model specific parameters can be calculated and correlated with patient specific parameters to explain inter-individual variability in response. Such an analysis can be useful in determining the applicability of low-dose spinal anesthetic techniques in the outpatient setting.

The purpose of the present study was to apply a population pharmacodynamic modelling approach to data from a spinal anesthesia study employing lowdose hypobaric lidocaine for outpatient laparoscopy.

Methods

The study was approved by the University Ethics Committee and informed consent was obtained from each patient. Patients scheduled for outpatient laparoscopy were assigned to receive spinal anesthesia with 20-25 mg lidocaine $1 \%$ (2-2.5 ml, Astra Zeneca, Mississauga, Ontario, Canada), mixed with 10-25 $\mu \mathrm{g}$ fentanyl $(0.2-0.5 \mathrm{ml})$ and sterile water $(0.5 \mathrm{ml})$. Patients were excluded if there was a contraindication to spinal anesthesia or to the spinal drugs. The spinal puncture was performed with a 27-G Whitacre needle with the patient in the sitting position. Spinal puncture was performed at $\mathrm{L}_{2-3}$ or $\mathrm{L}_{3-4}$. The spinal solution was injected rapidly $\left(0.5 \mathrm{ml} \cdot \mathrm{sec}^{-1}\right)^{3}$ with the needle orifice pointing cephalad. After one minute, patients were placed in reverse Trendelenburg position (15-20) until the level of sensory anesthesia (tested to pinprick) reached $\mathrm{T}_{6}$. Patients were then returned to the horizontal position. Positioning was standardised in all patients. Sensory block was determined by pinprick with an 18-gauge needle at 15 min intervals commencing at 15 min after injection (patients 1-43) and at five minute intervals commencing at five minutes post injection for the first two observations and then at $15 \mathrm{~min}$ intervals for the later observations (patients 44-57). Observations were continued for up to $150 \mathrm{~min}$ after spinal injection. All assessments were performed by one of the investigators. The dermatome level measurements were expressed in increasing numbers between $1\left(\mathrm{~S}_{5}\right)$ and $22\left(\mathrm{~T}_{1}\right)$. All observations were discontinued when the patient was ready for discharge and the sensory block had resolved. Fifty-seven subjects with a total of 385 measurements (4-11 per patient) over 5-150 min were available for this analysis.

The structural model used for the analysis was: $\mathrm{L}(\mathrm{t})=\mathrm{DOSE} \cdot \mathrm{CO} \cdot\left(\mathrm{e}_{1}^{-\mathrm{t}}-\mathrm{e}_{2}^{-\mathrm{t}}\right)$, where $\mathrm{L}(\mathrm{t})$ is the level of neural blockade. This model shows that the level of neural blockade is proportional to the dose of injection, equal to zero at $\mathrm{t}=0$ (injection time) and $\mathrm{t}=$ (long time from injection), and reaches its maximum some time after injection depending on (the absorption rate) and ${ }_{2}$ (the elimination rate). Schnider et al. ${ }^{4}$ called the model (Model $l$ in their paper) a combination of a biexponential pharmacokinetic model, describing the onset and offset of effect and, a linear pharmacodynamic model. Since all patients in the study received a small dose of lidocaine $1 \%(20-25 \mathrm{mg})$, we can take DOSE $=1$, which means that we do not look at dose as a covariate. The volume of injectate and the site of injection were also not looked at as covariates. As in Schnider et al., ${ }^{4}$ we assumed that $\mathrm{CO}_{\mathrm{i}}{ }_{1 \mathrm{i}}$, and ${ }_{2 \mathrm{i}}$, the parameters for the $\mathrm{i}^{\text {th }}$ patient, were log normally distributed with diagonal covariance matrix having diagonal elements $\left({ }_{1}^{2},{ }_{2}^{2},{ }_{3}^{2}\right)$. The residual errors for the $\mathrm{i}^{\text {th }}$ patient are assumed to be independently and identically normally distributed with mean zero and variance ${ }^{2}$ (common for all patients). We used NLME in statistical software S-plus to carry out our analysis. Like GLM for generalized linear models in S-plus, NLME is a flexible function for fitting non-linear mixed-effects models which is quite easy to use. Subsequently, clinically important endpoints were derived from the estimated

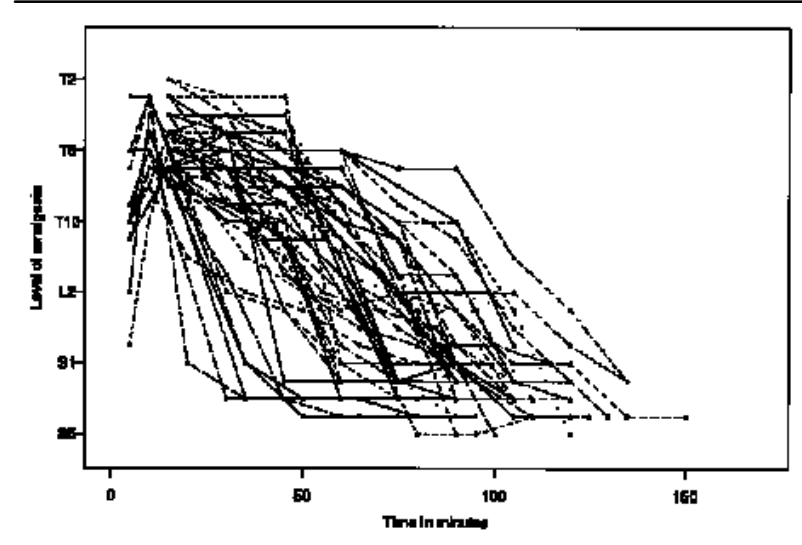

FIGURE 1 Scatter plot of observed levels of analgesia over time. The measurements for the same patient are connected with lines. 
TABLE I Population on parameters for Model 1

\begin{tabular}{lll}
\hline Parameter & Estimate & SE \\
\hline $\mathrm{lco}$ & 3.790 & 0.092 \\
$\mathrm{l} \alpha_{1}$ & -3.660 & 0.069 \\
$\mathrm{l}_{2}$ & -2.458 & 0.082 \\
$\sigma$ & 2.168 & - \\
$\omega_{1}$ & 0.003 & - \\
$\omega_{2}$ & 0.332 & - \\
$\omega_{3}$ & 0.305 & - \\
\hline
\end{tabular}

TABLE II Summary of the clinically important endpoints

\begin{tabular}{|c|c|c|c|c|c|c|c|}
\hline Endpoints & Mean & $S D$ & Min & $Q 1$ & Median & Q3 & $\operatorname{Max}$ \\
\hline $\begin{array}{l}\text { Time to reach } \mathrm{T}_{10} \\
\text { (onset) min }\end{array}$ & 8.3 & 1.9 & 3 & 7 & 8 & 10 & 12 \\
\hline $\begin{array}{l}\text { Time to reach } \\
\text { maximal level (min) } \\
\text { Duration }\end{array}$ & 20.8 & 5.3 & 8 & 18 & 21 & 24 & 34 \\
\hline $\begin{array}{l}\left.\text { (time above } \mathrm{T}_{1}\right) \mathrm{min} \\
\text { Maximally attained }\end{array}$ & 37.9 & 13.1 & 11 & 29 & 39 & 47 & 72 \\
\hline level* & 18 & 1.6 & 14 & 17 & 18 & 19 & 22 \\
\hline
\end{tabular}

* In increasing numbers starting with $\mathrm{l}=\mathrm{S}_{5}$ all the way to $22=\mathrm{T}_{1}$

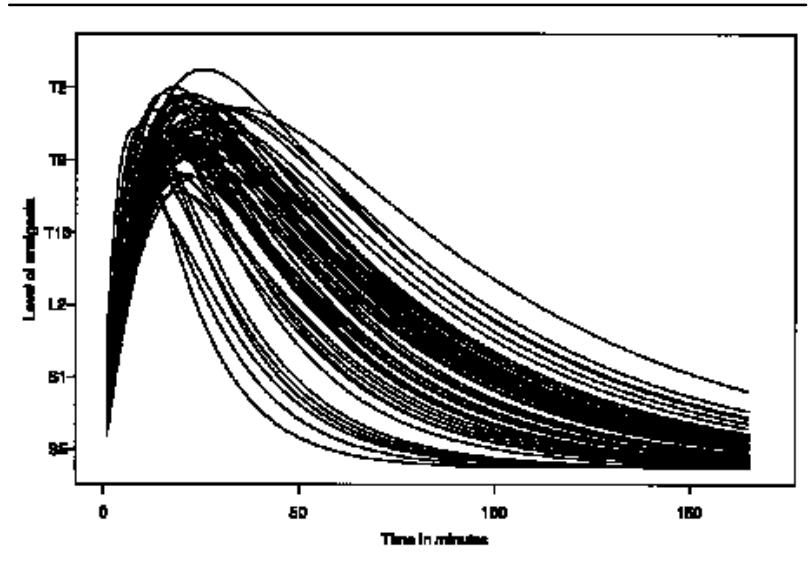

FIGURE 2 The estimated time course of analgesia levels for individual patients.

time course of analgesia level for each patient. These were: time to reach $\mathrm{T}_{10}$ (onset time), time to reach maximal level, duration of analgesia (time to analgesia $\mathrm{T}_{10}$ ), and the maximally attained level. The endpoints were numerically approximated. That is, we calculated the values of the estimated neural blockade level at 165 time points $(t=1,2, \ldots 165)$ for each patient, then found the approximated endpoints based on the 165 values.
The influence of the covariates height and weight on the clinical endpoints were explored subsequently. Finally, we used information from the onset of effect to predict the later data using the method described by Schnider et al. ${ }^{4}$

Results

Data

A satisfactory block was produced in all patients studied. A scatter plot of observed analgesia levels over time of all 57 patients is shown in Figure 1. Separate scatter plots of observed analgesia levels of each patient show a peak between zero and $45 \mathrm{~min}$ after insertion of the spinal anesthetic. The overall nature of the plots varied considerably from patient to patient. This suggests a nonlinear model to explain analgesia as a function of time but with parameters that vary from patient to patient.

\section{Model fitting}

Following Schnider et al., ${ }^{4}$ we first modelled the data for each individual patient using their Model 1:

$$
\mathrm{L}(\mathrm{t})=\operatorname{DOSE} \cdot \mathrm{CO} \cdot\left(\mathrm{e}_{1}^{-} \mathrm{t}_{-} \mathrm{e}_{2}^{-\mathrm{t}}\right) \text {. }
$$

Table I lists the estimated population parameters for Model 1. Each of the regression parameters is highly significant. On the other hand, the estimated value of ${ }^{\wedge}=2.168$ indicates that a considerable amount of the variability in the data is not explained by Model 1. The estimated variance components indicate that there is little variation from patient to patient in the values of $\mathrm{CO}_{\mathrm{i}}$, but considerable variation in the values of ${ }_{1 \mathrm{i}}$ and ${ }_{2 \mathrm{i}}$.

Figure 2 shows the estimated time course of analgesia levels in individual patients. The maximal level in these 57 patients varied between $\mathrm{T}_{9}$ and $\mathrm{T}_{1}$. Figure 3 presents the time course of the best, median and worst predicted profiles, as judged by the sum of squared residuals (per time point) from Model 1. Figure 4 gives the various plots of the residuals. The plot of observed $v s$ fitted values indicates that the model fits the data well; the correlation between the observed and fitted values was 0.95 . The plot of residuals $v s$ fitted values does not indicate any extreme departures from the assumptions in the model. The boxplots of the residuals for each individual patient show that, for most patients, the residuals are reasonably symmetrically scattered around zero.

\section{Calculation of clinical endpoints}

Based on the estimated time course of analgesia for each patient, we calculated the clinically important endpoints (Table II). The distribution of the different measures 

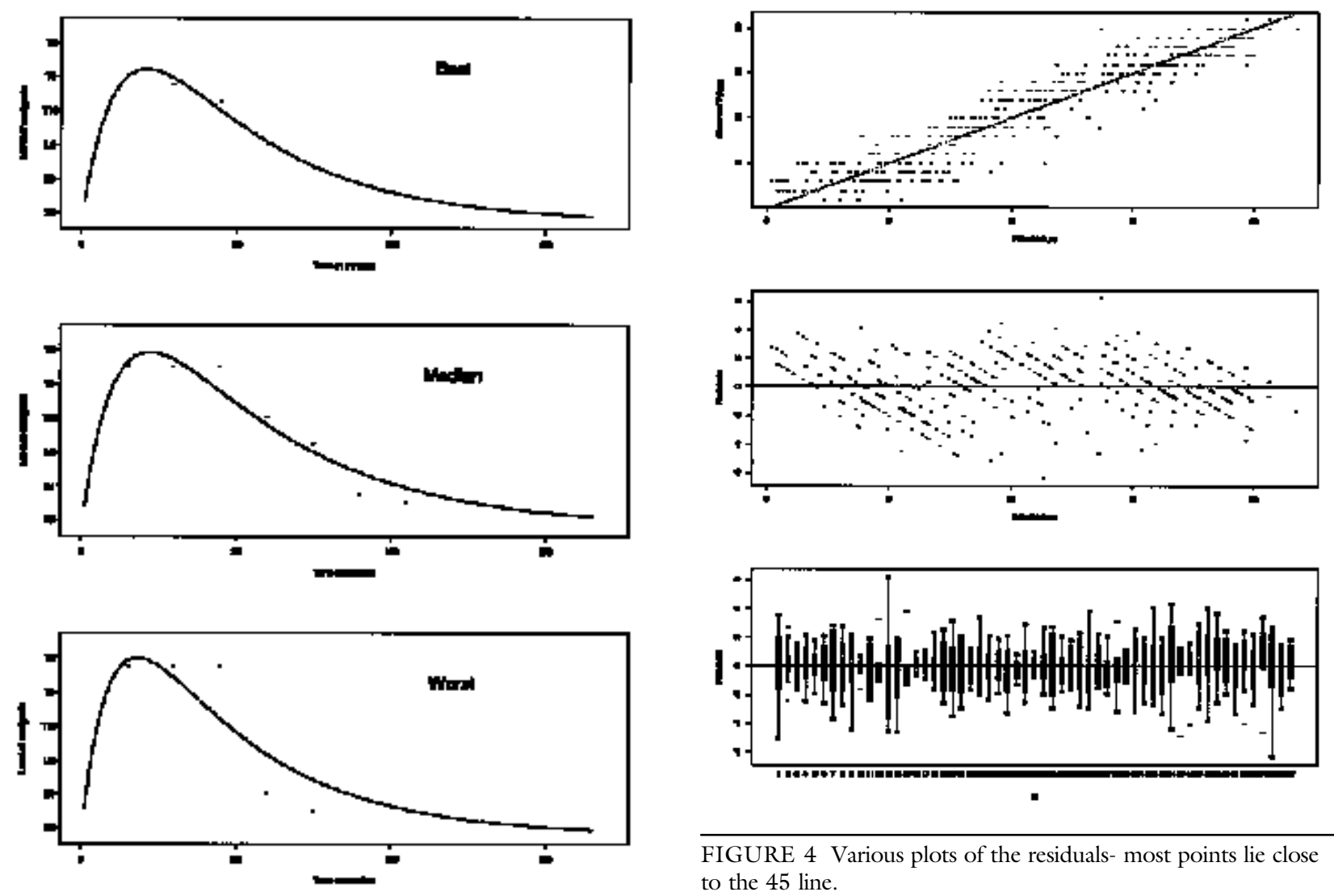

FIGURE 4 Various plots of the residuals- most points lie close to the 45 line.

FIGURE 3 The time course of the best, median, and worst predicted profiles from Model 1.

across the patient population is shown in Figure 5. The mean time to reach $\mathrm{T}_{10}$ was $8.3 \mathrm{~min}$ (median $8 \mathrm{~min}$ ). A mean level of analgesia of $\mathrm{T}_{5}$ was reached (median $\mathrm{T}_{5}$ ). The mean duration was $37 \mathrm{~min}$ (median $39 \mathrm{~min}$ ) and the mean time to reach maximal level was $20 \mathrm{~min}$ (median $21 \mathrm{~min}$ ). Height and weight were not found to significantly influence these clinical endpoints.

\section{Forecasting}

Model 1 was used to forecast observations beyond 75 min based on all observation times up to $75 \mathrm{~min}$ (total 288 observations). Figure 6 shows the plot of observed levels of analgesia (for all times $>75 \mathrm{~min}$ ) vs predicted levels; the correlation between observed and predicted values was $0.62(\mathrm{R}=0.38)$.

\section{Discussion}

In a study of 57 outpatients who received spinal anesthesia with a small dose of lidocaine $1 \%(20-25 \mathrm{mg})$, 385 measurements of analgesia levels were utilized to

facilitate population pharmacodynamic modelling with a model previously described by Schnider et $a l .^{4}$ Each of the regression parameters for the model were found to be highly significant. There was a good correlation between observed and fitted values $\left(\mathrm{R}^{2}=0.90\right)$ indicating that the data fits the model well and there was no apparent extreme departure from the assumptions of the model. Clinically important endpoints calculated were: mean time to reach $\mathrm{T}_{10}$ (onset) of eight minutes, mean time to reach maximal level of $20 \mathrm{~min}$, mean duration of $37 \mathrm{~min}$ and the mean maximal level achieved of $\mathrm{T}_{5}$. Forecasting using the model and data up to $75 \mathrm{~min}$ predicted the later levels of spinal analgesia only moderately well $\left(\mathrm{R}^{2}=0.38, \mathrm{R}=62\right)$.

The model used in this study was previously described by Schnider et al. ${ }^{4}$ with intrathecal bupivacaine. It is useful when a different number of data points for each subject are recorded at different points in time and when enough data points are not available in patients to fit each one's analgesic response independently. In the present study, patients received slightly different doses of spinal lidocaine $(20-25 \mathrm{mg}$ ) 

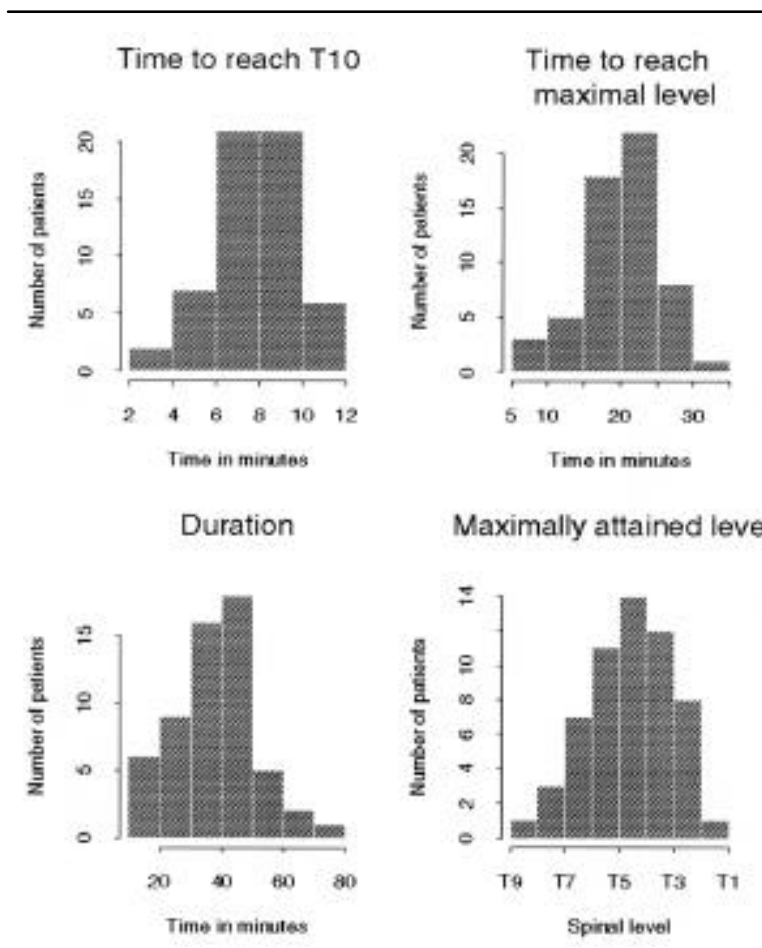

Maximally attained levels

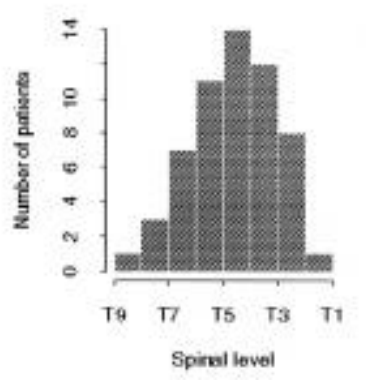

FIGURE 5 Distributions of the estimated clinically important endpoint.

and fentanyl (10-25 $\mu \mathrm{g})$ not unlike the patients in the study by Schnider. An important advantage of collecting observational data from normal clinical practice is that it reflects "real-life" data without controlling the independent variables by selecting a specific dose. The mixed-effects modelling approach used to derive the population model is especially useful when the data is unbalanced. Thus, conclusions, when drawn carefully, can have clinical applicability and relevance. Like Schnider, we treated the data as representing a continuous measurement and assumed that a change in analgesic level from $T_{8}$ to $T_{7}$, for example, was the same as a change from $S_{1}$ to $L_{5}$.

With intrathecal bupivacaine, Schnider's model was found to be successful with a close correlation $(\mathrm{R}=0.7)$ between observed and predicted levels of analgesia being found with forecasting based on observations in the first $30 \mathrm{~min}$. In our study, with low-dose lidocaine, Schnider's model was found to perform moderately well with correlation of 0.62 . Thus, for model fitting, our results were as good as Schnider $\left(\mathrm{R}^{2}=0.95\right.$ vs $\mathrm{R}^{2}=0.9$ ). For model forecasting, their results were better than ours $\left(\mathrm{R}^{2}=0.7\right.$ vs $\left.\mathrm{R}^{2}=0.38\right)$ because we did not have sufficient earlier observations. Another reason for

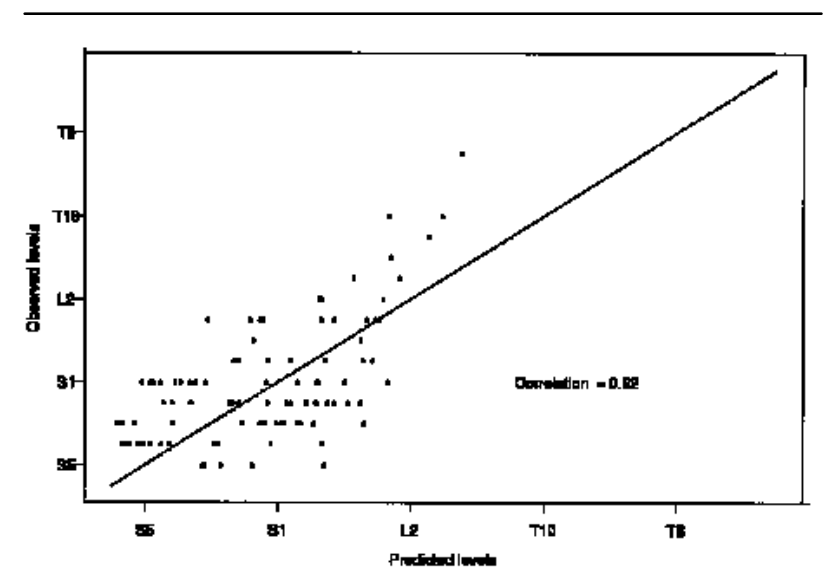

FIGURE 6 Observed $v s$ predicted levels of analgesia (for all levels at times $>75 \mathrm{~min}$ ). These predicted levels are based on the individual patient parameters obtained from all the observations in the first $75 \mathrm{~min}$.

Schnider's results being better than ours could be that we had fewer data (385 observations in 57 subjects) than Schnider (714 observations in 96 subjects). In the present study, we could not forecast offset effects but only the observations later than 75 min because we did not have enough "onset" observations. The model might be used for forecasting offset effect with smalldose spinal anesthesia, if we had more earlier observations. Given the apparent timing of the maximal levels, more frequent measurements right after insertion of spinal anesthetic are required to provide good fits of either of these models for these data. More early observations would also improve the prediction of the offset effect based on early measurements. Schnider also found that inter-individual variability in analgesic levels could be explained in part by covariates such as height and weight. In the present study, very little of the variation in any of the clinical endpoints was explained by height and weight. Other factors such as patient position could also be important in influencing the spread of analgesia and hence contribute to the variability of inter-individual data sets. ${ }^{5}$ All patients in this study were managed in a standard manner with respect to position change after completion of spinal injection to minimize this source of data imbalance. Because position change was not a part of the model, it would contribute to a deviation between observed and predicted levels of analgesia and become part of the residual error. However, because our data represents actual observational data from "real life" clinical practice, it has the strength of clinical relevance and applicability. 
We also explored several other fits to the data. Using the same model, we fitted the data allowing the patient level parameters to be arbitrarily correlated and with the residual errors assumed to be independent and normally distributed with: (a) common variances; (b) variances that vary exponentially with the absolute values of the predicted values. The resulting fitted curves were similar to those illustrated in Figure 2.

Schnider et al. ${ }^{4}$ used two models, and they indicated that Model 2 provided a better fit to their data than Model 1. Model 2 is presented in the Appendix of their paper as:

$$
\mathrm{L}_{2}(\mathrm{t})=\mathrm{EM} \cdot\left[\operatorname{DOSE} \cdot\left(\mathrm{e}_{1}^{-}{ }_{1}^{\mathrm{t}} \mathrm{e}_{2}^{-\mathrm{t}}\right) / \mathrm{F}+\operatorname{DOSE} \cdot\left(\mathrm{e}_{1}^{-} \mathrm{t}_{-} \mathrm{e}_{2}^{-\mathrm{t}}\right)\right] \text {. }
$$

With this definition, $\mathrm{L}_{2}(\mathrm{t})$ is a decreasing function of $\mathrm{t}$, which means that this model is not suitable for the sensory data. Clearly, this is not the model they used in their paper. It seems likely that the actual model used by Schnider et al. ${ }^{4}$ as Model 2 was:

$$
\mathrm{L}_{2}{ }^{*}(\mathrm{t})=\mathrm{EM} \cdot\left[\operatorname{DOSE} \cdot\left(\mathrm{e}^{-}{ }_{1}^{\mathrm{t}}-\mathrm{e}_{2}^{-\mathrm{t}}\right) / \mathrm{F}+\operatorname{DOSE} \cdot\left(\mathrm{e}^{-}{ }_{1}^{\mathrm{t}}-\mathrm{e}_{2}^{-\mathrm{t}}\right)\right] \text {. }
$$

We also fitted our data to the function $\mathrm{L}_{2}{ }^{*}(\mathrm{t})$, with the same assumptions on the parameters used by Schnider et al. ${ }^{4}$ This model seems to be unsuitable for our data set, as the fitted curves reflected very little patient to patient variability. We do not present the results in this paper since we are not sure of the correct definition of their Model 2. Schnider et al. ${ }^{4}$ do not indicate why they assumed that there was no correlation between the patient-level parameters. Perhaps this was a limitation of the software they employed to perform the fitting. They indicated that the software NONMEM was used to carry out their analysis, we used NLME in S-plus. Like GLM for generalised linear models in S-plus, NLME is a flexible function for fitting non-linear random effects models which is quite easy to use.

In summary, we tested a mixed-effects model for the description of analgesia levels over time after the administration of small-dose lidocaine-fentanyl spinal anesthesia to outpatients undergoing gynecological laparoscopy. Clinically important endpoints were obtained for low-dose lidocaine spinal anesthesia. There was a good correlation between observed and predicted levels of analgesia.

\section{References}

1 Vaghadia $H$. Spinal anaesthesia for outpatients: controversies and new techniques. Can J Anaesth 1998; 45: R64-R70.

2 Vaghadia H, McLeod DH, Mitchell GWE, Merrick PM, Chilvers CR. Small-dose hypobaric lidocaine- fentanyl spinal anesthesia for short duration laparoscopy. I. A randomized comparison with conventional dose hyperbaric lidocaine. Anesth Analg 1997; 84: 59-64.

3 Chilvers CR, Vaghadia H, Mitchell GWE, Merrick PM. Small-dose hypobaric lidocaine-fentanyl spinal anesthesia for short duration outpatient laparoscopy. II. Optimal fentanyl dose. Anesth Analg 1997; 84: 65-70. 4 Schnider TW, Minto CF, Bruckert H, Manderna JW. Population pharmacodynamic modeling and covariate detection for central neural blockade. Anesthesiology 1996; 85: 502-12.

5 Russell IF. Posture and isobaric subarachnoid anaesthesia. The influence on spread of spinal anesthesia with 'isobaric' 0.5\% bupivacaine plain. Anaesthesia 1984; 39: 865-7. 